\title{
Photoelectric Spectroradiometry and Its Application to the Measurement of Fluorescent Lamps
}

\author{
Ralph Stair
}

\begin{abstract}
This paper describes new equipment and its applications in the precise determination of the spectral radiant energy emission of light sources having low intrinsic brightness, in particular fluorescent lamps. The evaluation of the spectral radiant energy distribution of light sources having superimposed bright lines is discussed in detail. Data are given on a number of commercially available fluorescent sources. Applications are noted in other problems, for example absolute spectral emissivity measurements on tungsten, spectral reflectivities, spectral transmittance measurements on dark shade welding glass, total ozone studies, or measurements in other situations where low intensities may be involved.
\end{abstract}

\section{Introduction}

The production of light (or other radiant energy) through the frequency changing process within a fluorescent lamp tube, wherein the generated radiant energy (principally) of wavelength $2537 \mathrm{~A}$ is emitted through a band of frequencies (wavelengths) extending over an appreciable spectral range, results in sources of high luminous (or radiant) efficiency but of low intrinsic surface brightness. The low radiant intensity per unit area makes it difficult to determine accurately the spectral radiant intensity with ordinary spectrophotometric apparatus. Precise measurements are further complicated by the presence of mercury emission lines superimposed upon the continuous fluorescent spectrum. These lines contribute appreciably to the color of the lamps and hence to their relative spectral quality and must therefore be accurately evaluated in any precise spectral energy measurements.

It is a fortunate circumstance that many of the available phosphors have a maximum spectral excitation sensitivity near the wavelength $2537 \mathrm{~A}$ in the mercury emission spectrum, especially since approximately one-half of the wattage dissipated within the low pressure mercury arc discharge is emitted at this wavelength. Otherwise the surface brightness of fluorescent lamps would be even lower.

The introduction of fluorescent lighting into the many industries and pursuits of man has aroused much interest in its relationship to colors, whether it be that of a paint, a dyed fabric, a chemical reaction, or even an individual's facial appearance $[1,2] .{ }^{1}$ It is recognized that the simple matching of a fluorescent lamp color to a particular tungsten filament color temperature, or to average daylight, does not insure equal color appearance of the illuminated object. A food, for example an egg, an orange, or an apple may appear unappetizing under a fluorescent lamp, which matches perfectly average daylight in over-all color. A vegetable, flower, or garment may likewise appear of different hue. The spectral quality of the two sources also must be considered since

${ }^{1}$ Figures in brackets indicate the literature references at the end of this paper. the colors of the materials, whether they be food, flowers, clothing, household furnishings, or a human face depend upon both the optical spectral reflective characteristics of the material and upon the relative spectral radiant energy distribution of the source of illumination.

The recent widespread use and diversity of colors of fluorescent lamps, as improvements and changes are made in the composition or treatment of the phosphors, have resulted in an increased demand for more precise information regarding their spectral emission characteristics. It is the primary purpose of this report to describe a new instrument and its application to this problem.

\section{Instruments and Methods}

\section{Spectroradiometer}

A double quartz prism spectrometer, manufactured by the Farrand Optical Co., has been modified slightly for use in this investigation. (See fig. 1.) This instrument employs two sets of paired 30deg crystalline quartz prisms. The lenses are of $30 \mathrm{~cm}$ focal length, have $75-\mathrm{mm}$ free aperture, and are doublets, constructed of quartz-lithium fluoride and achromatized at two positions within the ultraviolet spectrum (about 220 and $400 \mathrm{~m} \mu$ ). The slits are each manually adjustable. The entrance and exit slits are straight, the center slit being curved. Changes in wavelength are accomplished through a tandem drive that rotates the four prisms arranged in Thollon type mountings. All other optical components of the instrument are fixed in position.

For recording purposes a three-speed reversiblegear drive from a small synchronous motor was attached to the center wavelength adjusting knob (shaft). These three speeds allow scanning the spectrum from 200 to $780 \mathrm{~m} \mu$ in about 4 , 8, or 12 min in either direction. Since the calibrating factors are slightly different for the two directions all measurements, in the present investigation, were made with increasing wavelength. Cams and switches are provided to automatically stop the 


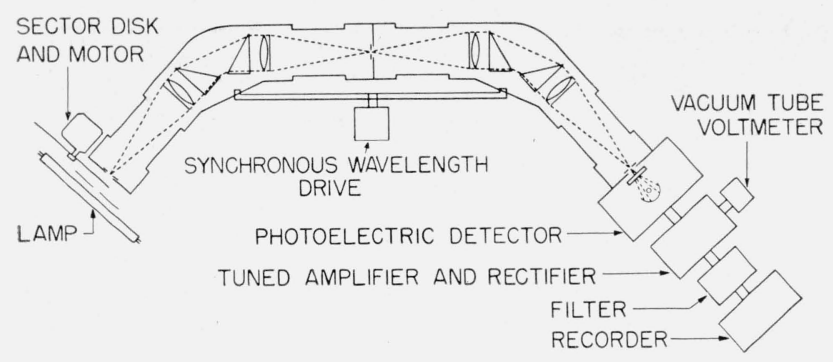

FIGURE 1. Diagrammatical layout of Farrand double monochromator and associated equipment as employed in fuorescent lamp measurements.

motor drive at either end of the spectrum and to give index marks on the recorder chart, by means of an auxiliary pen, at 18 positions (equally spaced in wave number) through the spectrum. For manual operation the motor drive is simply disengaged.

A sector disk having 17 equally spaced openings and operated at 1,800 rpm by a synchronous motor modulates the light beam at $510 \mathrm{c} / \mathrm{s}$ before it enters the spectrometer. This frequency was chosen as one of the possible ones between 500 and 1,000 cycles that could be easily obtained by means of the disk and motor setup and that was incommensurate with any of the harmonics of the light and power frequencies. The use of a modulated light beam makes possible the employment of this instrument in a fully lighted room having normal light fluctuations, without noticeable effect upon the recorded data, as only changes within the light beam path are registered and then only if at a frequency near that of the light modulation. Disk openings of circular shape give approximately sinusoidal light modulation. They require a disk of larger diameter than do angular openings which result in the generation of an approximately square wave. Either type gives satisfactory performance.

The photoelectric detectors employed in this instrument in the present work are a standard blue sensitive (RCA 935) and a red sensitive (GE PJ-14B) to cover the range of about 250 to $780^{2} \mathrm{~m} \mu$. A quartz tube having an S-4 (blue sensitive) surface is available for use with the short wavelengths. Other types of standard or special tubes are of course adaptable for use in this instrument.

\section{Tuned Amplifier}

A tuned amplifier (see fig. 2) peaked at $510 \mathrm{c} / \mathrm{s}$ has certain characteristics that may be noted [3]. The input stage employs a specially selected tube for high signal to noise ratio, the type 1620 . This stage circuit is designed for high signal gain with little attention being given to frequency shaping.

The second stage, employing a $6 \mathrm{SJ} 7$ tube, contains a tuned secondary consisting of a high $Q$ variable inductor shunted by a fixed mica condenser. This combination results in a band pass of about 100 cycles. The amplifier is stable at all gain settings, yet has a sufficiently narrow pass band to reduce noise and power line frequencies to a relatively low level. The pass band peak is sufficiently broad, however, when properly adjusted to 510 cycles, that normal fluctuations in the power line frequency are unnoticeable.

${ }^{2}$ In the present case the short wavelength limit is determined by the lamp standards, the long wavelength by the mechanics of the spectrometer.

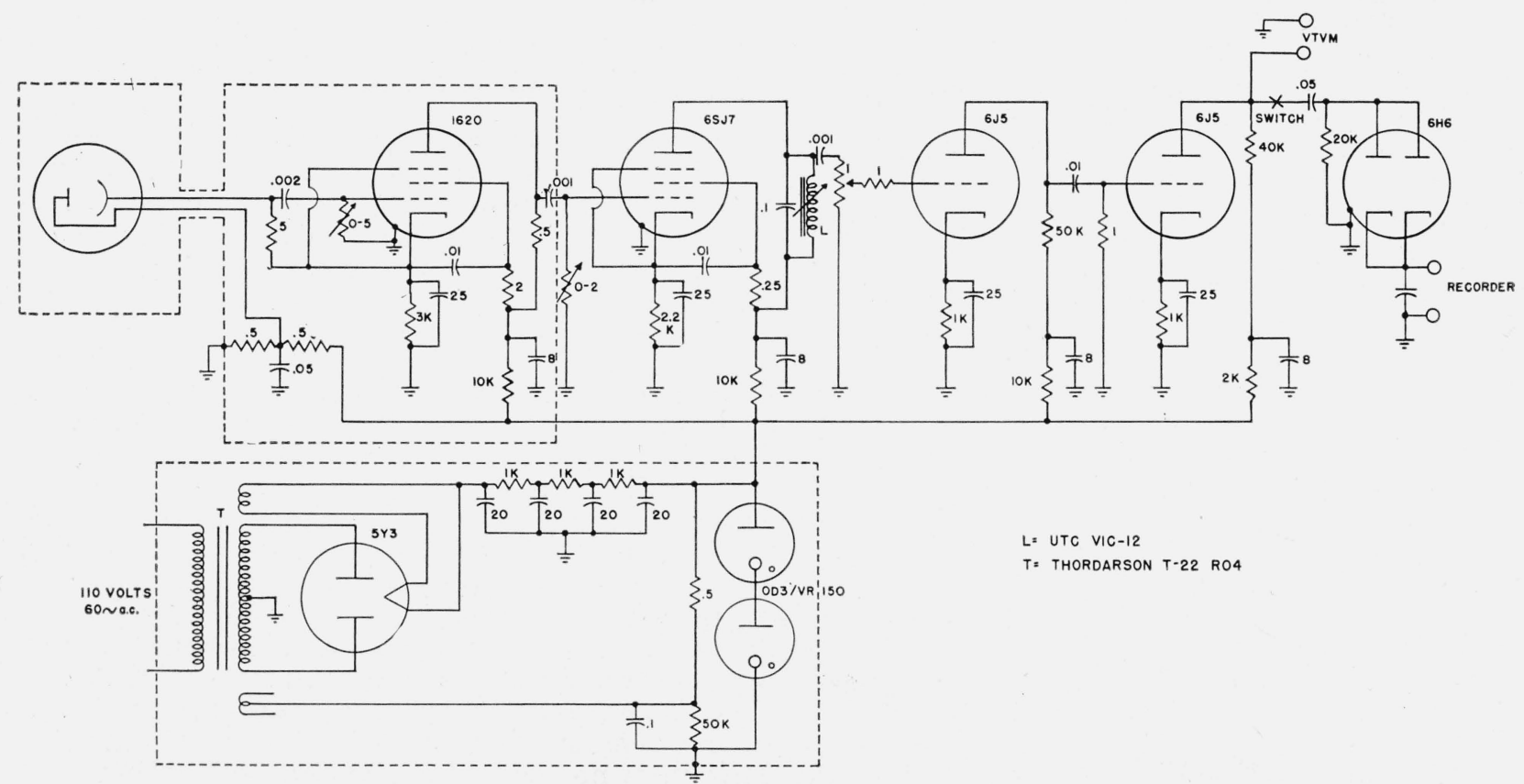

FIGURE 2. Electronic circuit employed in 510-cycle-per-second tuned amplifier. Resistances in megohms and capacitances in microfarads except as otherwise noted. 
Amplifier gain is controlled by a tandem duogrid variable resistance linkage in the second and third stages. The gain is fixed in the first and fourth stages, except that provision is made for substituting the proper value of grid resistor in the first stage for the problem at hand. Ample shielding of the first stage and of the second and third stage grid connections reduces pick-up noises to a minimum. Sufficient space between amplifier stages (which are arranged in line) and individual plate-supply filternetworks reduces positive amplifier coupling to a negligible value. The use of an isolated powersupply chassis eliminates transformer magnetic fields within the amplifier, thus reducing 60 - and 120 -cycle hum.

The output of the amplifier is connected with a vacuum-tube voltmeter (Ballantine model 300), or after rectification by a $6 \mathrm{H} 6$ twin diode the resulting direct current is fed through a filter and into a standard commercially available Leeds \& Northrup Speedomax recorder. The alternating-current output is linear for all values below about $20 \mathrm{v}$. Recorded direct-current values are slightly nonlinear as the result of contact potential within the $6 \mathrm{H} 6$ diode rectifier. Increased linearity is obtained with increased load resistance. Various circuits have been employed for eliminating nonlinearity, among these being the use of a balanced direct-current amplifier [4] or balanced cathode follower. Usually, however, the resulting zero drift counterbalances any gains obtained over the use of the standard diode rectifier circuit, which is illustrated in figure 2 . With this circuit the zero is stable, and a linearity correction is easily made. However, it is often preferable in precision work to also read the intensity values directly on the alternating-current vacuum-tube voltmeter and manually plot the resulting data. Most of the data displayed in this report were obtained by the latter method, the recorder curves being employed primarily as supplementary aids.

\section{Standards of Radiant Energy}

The precise evaluation of radiant energy requires the use of a standard on which the measurements are based. At this Bureau all work of this type is necessarily referred to a fundamental black body. In practice, however, thermal standards [5] that have been prepared in the form of carbon filament lamps are employed. In the present work secondary standards in the form of a special tungsten-in-quartz lamp [6] and a quartz mercury-are lamp [7] are required to obtain a precise calibration of the spectrometer for use with a continuous source having superimposed bright lines.

\section{(a) Tungsten-Filament in Quartz Lamp}

The tungsten-filament-in-quartz lamp employed in this work (see fig. 3) is of special construction by the Westinghouse Electric Corp. It is based upon a laboratory model described in a previous report [6]. It is constructed of drawn tungsten wire arranged in a plane formed by a series of "hair-pin" loops. The

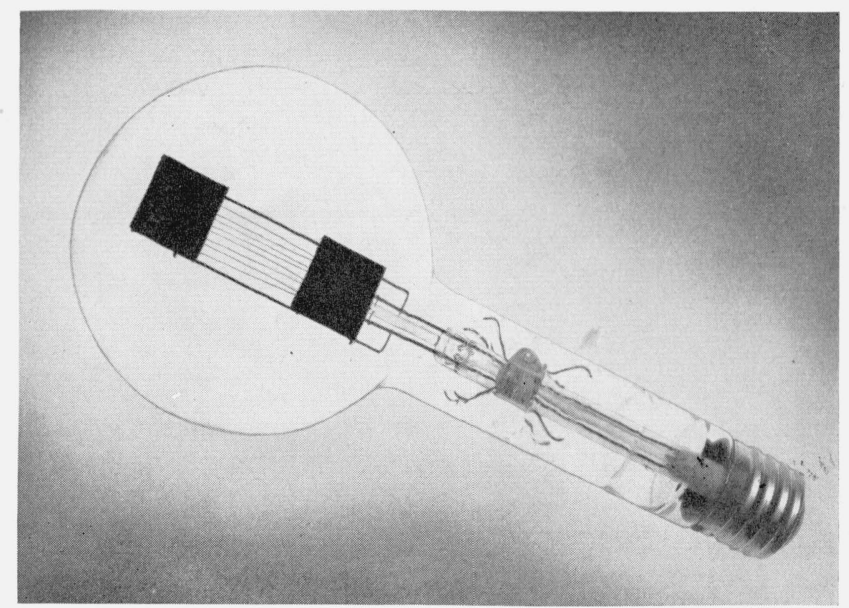

FIGURE 3. Tungsten-filament-in-quartz standard lamp.

filament wires are evenly spaced, uncoiled, and covered by shields at the looped ends in order to insure approximately uniform temperatures throughout the filament area. The use of a high quality fused silica bulb permits a high transmittance of radiant energy throughout the region from below 250 to above 2,000 $\mathrm{m} \mu$. The high quality of the fused silica envelope allows the employment of a projection system where the use of a single filament wire is desired. However, in the present work no projection system is needed or desired. The light from the complete lamp is simply allowed to fall directly upon the entrance slit of the spectrometer.

The spectral distribution of the radiant energy from a lamp of this type is a function of the filament temperature, the emissivity of the material composing the filament, and the transmittance of the lamp envelope. For this purpose, therefore, black-body radiant energy, the emissivity of tungsten, and the transmittance of the fused-quartz envelope must be considered. The relative spectral radiant intensity from a black body depends only upon the temperature. Data for any desired temperature may be calculated through the use of the Planck radiation law. However, data may be found in the literature [24 to 26$]$.

The emissivity of tungsten has been determined by a number of workers [8 to 11] for different temperatures. Until better data are available we are necessarily making use of a weighted mean curve of the published values for a filament temperature of about $2,900^{\circ} \mathrm{K}$ [6]. These values are probably adequate in radiometric work for a temperature range of 200 to $300 \mathrm{deg}$. The values employed in the present work are tabulated in table 3 for selected wavelengths.

As the transmittance of the fused silica envelope in the spectal region of 250 to $2,000 \mathrm{~m} \mu$ is nearly uniform, no correction is necessary in most practical applications of the lamp. Any deviation from uniformity is no doubt exceeded by lack of accurate knowledge on relative spectral emissivity within the spectral range employed in the present work. There- 
fore, in the present case no note is taken of the transmission characteristics of the lamp-envelope. The method for the absolute calibration of this lamp is displayed in tables 1,2 , and 3 .

TABLE 1. Calibration of quartz mercury arc lamp for radiant energy of $365.5 \mathrm{m \mu}$ at $1.121 \mathrm{~m}$

\begin{tabular}{|c|c|}
\hline Output of thermal standard of radiation, $\left(\mu \mathrm{w} / \mathrm{cm}^{2}\right)$. & 37.9 \\
\hline Galvanometer deflection, $\mathrm{cm}$ & 9. 58 \\
\hline $\begin{array}{l}\mu \mathrm{w} / \mathrm{cm}^{2} \text { per } \mathrm{cm} \text { deflection } \\
\text { alvanometer deflection for } \mathrm{Hg} \text { are lamp (with } \mathrm{G} 5860 \text { filter, }\end{array}$ & $\begin{array}{l}3.956 \\
9.206\end{array}$ \\
\hline $\begin{array}{l}\text { transmittance } 0.324 \text { at } 365.5 \mathrm{~m} \mu) \text { at } 50.7 \mathrm{~cm} \text {. } \\
\text { Radiant energy (mainly } 365.5 \mathrm{~m} \mu)^{\mathrm{a}} \text { from } \mathrm{Hg} \text { are through filter, } \\
\mu \mathrm{w} / \mathrm{cm}^{2}(\mathrm{at} 50.7 \mathrm{~cm})\end{array}$ & 36.42 \\
\hline $\begin{array}{l}\mu \mathrm{w} / \mathrm{cm}^{2} \text { ent radiant energy of } 365.5 \mathrm{~m} \mu \text { from lamp, } \mu \mathrm{w} / \mathrm{cm}^{2} \text { (at } \\
50.7 \mathrm{~cm} \text { ). }\end{array}$ & 112.4 \\
\hline $\begin{array}{l}\text { Equivalent radiant energy of } 365.5 \mathrm{~m} \mu \text { from lamp, } \mu \mathrm{w} / \mathrm{cm}^{2} \text { at } \\
1.121 \mathrm{~m} \text { (calculated). }\end{array}$ & 23.0 \\
\hline True radiant energy of $365.5 \mathrm{~m} \mu$ from lamp, $\mu \mathrm{w} / \mathrm{cm}^{2}$ at $1.121 \mathrm{~m}$ & 22.54 \\
\hline
\end{tabular}

a About $2 \%$ of the radiant energy from the quartz $\mathrm{Hg}$ are lamp transmitted difference of the sums given in insertions 7 and 8 .

TABLE 2. Calibration of 935 phototube radiation meter (phototube covered with 65860 filter)

\begin{tabular}{|c|c|}
\hline $\begin{array}{l}\text { Standard } \mathrm{Hg} \text { arc lamp, equivalent radiant energy of } 365.5 \mathrm{~m} \mu \text { at } \\
1.121 \mathrm{~m}, \mu \mathrm{W} / \mathrm{em}^{2} .\end{array}$ & a 23.00 \\
\hline Same, transmitted by G5860 filter $\left(T_{365.5}=0.324\right), \mu \mathrm{w} / \mathrm{cm}^{2}$ & 7.45 \\
\hline $\begin{array}{l}\text { Observed meter reading, } \mu \text { a } \\
\text { Calculated value } \mu \mathrm{w} / \mathrm{cm}^{2} \text { per } \mu \mathrm{a} \text { of } 365.5 \mathrm{mu}(745 / 403)\end{array}$ & $\begin{array}{l}4.03 \\
1.85\end{array}$ \\
\hline
\end{tabular}

a This value rather than 22.54 (see table 1) is used, since energy of both wave lengths 334.2 and 365.5 is transmitted by filter G5860, and since the response of phototube 935 is approximately the same for these two wavelengths.

TABLE 3. Calibration of standard tungsten filament in quartz lamp for use with the spectrometer a

\begin{tabular}{|c|c|c|c|c|c|c|c|c|}
\hline $\begin{array}{c}\text { Center } \\
\text { of wave } \\
\text { length } \\
\text { interval }\end{array}$ & $\begin{array}{c}\text { Rela- } \\
\text { tive } \\
\text { energy } \\
\text { black } \\
\text { body } \\
2945^{\circ} \\
\mathrm{K}, c_{2}= \\
14,380\end{array}$ & $\begin{array}{l}\text { Emis- } \\
\text { sivity } \\
\text { factor } \\
\text { for } \\
\text { tungs- } \\
\text { ten }\end{array}$ & $\begin{array}{c}\text { Rela- } \\
\text { tive } \\
\text { energy } \\
\text { from } \\
\text { tungs- } \\
\text { ten } \\
2945^{\circ} \\
\mathrm{K}, \\
\text { cols. } \\
2 \times 3\end{array}$ & $\begin{array}{l}\text { Trans. } \\
\text { G5860 } \\
\text { filter }\end{array}$ & $\begin{array}{l}\text { Rela- } \\
\text { tive } \\
\text { re- } \\
\text { sponse } \\
\text { type } \\
935 \\
\text { photo- } \\
\text { tube }\end{array}$ & $\begin{array}{c}\text { Relative } \\
\text { energy } \\
\text { measured } \\
\text { cols. } 4 \times \\
5 \times 6\end{array}$ & $\begin{array}{c}\text { Abso- } \\
\text { lute } \\
\text { energy } \\
\text { meas- } \\
\text { ured, } \\
\mu \mathrm{w} / \mathrm{cm}^{2} \\
\text { per } 5 \\
\mathrm{~m} \mu, \\
\text { through } \\
\text { filter }\end{array}$ & $\begin{array}{l}\text { Abso- } \\
\text { lute } \\
\text { energy } \\
\text { at } 17.1 \\
\mathrm{~cm} / \\
\mu \mathrm{w} / \\
\mathrm{cm}^{2} \\
\text { per } 5 \\
\mathrm{~m} \mu\end{array}$ \\
\hline $\begin{array}{c}m \mu \\
320 \\
325 \\
330 \\
335 \\
\end{array}$ & $\begin{array}{l}1990 \\
2310 \\
2690 \\
3100\end{array}$ & $\begin{array}{l}0.433 \\
.436 \\
.4385 \\
.441\end{array}$ & $\begin{array}{r}862 \\
1007 \\
1180 \\
1367\end{array}$ & $\begin{array}{l}\text { Per- } \\
\text { cent } \\
0.36 \\
1.56 \\
4.23 \\
8.83\end{array}$ & $\begin{array}{l}740 \\
752 \\
763 \\
772\end{array}$ & $\begin{array}{l}23 \times 10^{2} \\
118 \\
381 \\
932\end{array}$ & $\begin{array}{r}0.01 \\
.03 \\
.10 \\
.26\end{array}$ & $\begin{array}{l}1.88 \\
2.19 \\
2.57 \\
2.98\end{array}$ \\
\hline $\begin{array}{l}340 \\
345 \\
350 \\
355\end{array}$ & $\begin{array}{l}3580 \\
4100 \\
4690 \\
5300\end{array}$ & $\begin{array}{l}.443 \\
.445 \\
.446 \\
.447\end{array}$ & $\begin{array}{l}1586 \\
1825 \\
2092 \\
2369\end{array}$ & $\begin{array}{l}14.80 \\
21.20 \\
26.85 \\
30.95\end{array}$ & $\begin{array}{l}778 \\
782 \\
785 \\
790\end{array}$ & $\begin{array}{l}1826 \\
3026 \\
4409 \\
5792\end{array}$ & $\begin{array}{r}.50 \\
.83 \\
1.22 \\
1.60\end{array}$ & $\begin{array}{l}\text { 3. } 45 \\
\text { 3. } 97 \\
\text { 4. } 56 \\
5.16\end{array}$ \\
\hline $\begin{array}{l}360 \ldots \\
365 \\
370 \\
375 \\
375_{-}\end{array}$ & $\begin{array}{l}5980 \\
6720 \\
7820 \\
8390\end{array}$ & $\begin{array}{l}.448 \\
.449 \\
.450 \\
.450\end{array}$ & $\begin{array}{l}2679 \\
3017 \\
3384 \\
3776\end{array}$ & $\begin{array}{l}33.00 \\
32.40 \\
28.80 \\
20.90\end{array}$ & $\begin{array}{l}790 \\
790 \\
790 \\
788\end{array}$ & $\begin{array}{l}6984 \\
7722 \\
7699 \\
6219\end{array}$ & $\begin{array}{l}1.93 \\
2.13 \\
2.13 \\
1.72\end{array}$ & $\begin{array}{l}5.83 \\
6.57 \\
7.37 \\
8.22\end{array}$ \\
\hline $\begin{array}{l}380 \ldots \\
385-\ldots \\
390-\ldots-\end{array}$ & $\begin{array}{r}9310 \\
10210 \\
11370\end{array}$ & $\begin{array}{l}.451 \\
.451 \\
.455\end{array}$ & $\begin{array}{l}4199 \\
4605 \\
5043\end{array}$ & $\begin{array}{r}10.35 \\
2.73 \\
.18\end{array}$ & $\begin{array}{l}786 \\
782 \\
776\end{array}$ & $\begin{array}{r}3416 \\
983 \\
70\end{array}$ & $\begin{array}{r}0.94 \\
.27 \\
.02\end{array}$ & $\begin{array}{r}9.14 \\
10.03 \\
10.98\end{array}$ \\
\hline Total & & & & & & 49,600 & 13.69 & \\
\hline
\end{tabular}

a In this calibration the radiation meter reading (deflection) corresponding to the summation of 49,600 was $7.40 \mu \mathrm{a}$, with the lamp $17.1 \mathrm{~cm}$ from the meter.

The part of this reading resulting from the $5-\mathrm{m} \mu$ band centered at $365 \mathrm{~m} \mu$ is The part of this

$7,722 / 49,600=0.1556$.
Therefore, the part of the microammeter reading due to the $365-\mathrm{m} \mu$ band is Therefore, the part
$0.1556 \times 7.40=1.151 \mu \mathrm{a}$.

$0.1556 \times 7.40=1.151 \mu \mathrm{a}$.
Therefore, from table 2 , the absolute value of this $365-\mathrm{m} \mu$ band as measured is $1.151 \times 1.85=2.13 \mu \mathrm{w} / \mathrm{cm}^{2}$, as shown in column 8 . (Calculated values for the measured parts of the other bands are also given in this column).

The absolute energy value for the tungsten filament-in-quartz lamp for 365-m $\mu$

$\left(5 \mathrm{~m} \mu\right.$ ) band accordingly is $2.13 / 0.324=6.57 \mu \mathrm{w} / \mathrm{cm}^{2}$. Other values for the other

wavelength intervals are calculated from the column 4 tabulations. (b) Mercury Arc Line Source

The quartz mercury arc lamp employed as a standard line source has been previously described elsewhere [7]. It is a commercially available mercurypool 110-v direct-current Uviarc having about onethird of each end of the lamp tube shielded so that effects of end-blackening and arc-unsteadiness near the two ends of the tube are eliminated from the observations.

The intensity of the principal spectral lines from 365.5 to $578 \mathrm{~m} \mu$ are evaluated by means of a photoelectric radiation meter consisting of a 935 phototube (and associated electronic amplifier), a surface thermopile and associated galvanometer, and a group of glass filters. First, the absolute intensity of wavelength $365.5 \mathrm{~m} \mu$ is determined by the thermopile and galvanometer through the use of the Corning filter $\mathrm{G}$ 5860 , and a standard of thermal radiation [5]. (See table 1).

The relative intensities at the lines 405, 435.8, 546.1 , and $578 \mathrm{~m} \mu$ are next obtained simply through sets of measurements employing the photoelectric meter, or the thermopile and galvanometer, and a set of filters suitable for isolating the various mercury emission lines in groups of one, two, or even three and through a calculation of the resulting simultaneous equations. The intensities of the mercury lines tabulated in column 6 of table 4 were thus obtained at the distance of $72.6 \mathrm{~cm}$ from the lamp tube.

\section{(c) Evaluation of the Spectral Line Intensities in Terms of the Continuous Spectrum Parameters}

Since the spectral energy distribution from a fluorescent lamp consists of a continuous spectrum upon which is superimposed a series of bright lines, a special method must be developed for precise evaluation of the respective components concurrently present. Such an evaluation has been calculated by Mary P. Lord [12] and employed in revised form by Charles W. Jerome [13]. In the present work, however, the evaluating factor has been experimentally determined through the use of two standards of radiation - a tungsten-filament-in-quartz lamp and a mercury arc lamp. It was felt that the mechanical operation of a double monochromator could not be faithfully relied upon to follow a calculated relationship between line and continuous spectrum intensities for use in precise work. Indeed, experience has shown that neither of the instruments in this laboratory follows precisely a calculated intensity relationship.

In order to obtain a relationship between the response for spectral lines relative to a continuous spectrum, definite radiant energy intensities were admitted to the entrance slit of the spectrometer for the two types of radiant energy. For this purpose the mercury arc and the tungsten filament lamps were alternately placed at the calibrated distances from the spectrometer slit, which was covered with a plate of finely ground fused silica glass to insure uniform and complete illumination 
TABLE 4. Calibration of spectrometer for integrated response of spectral lines, using standard tungsten-in-quartz and quartzmercury arc lamps

\begin{tabular}{|c|c|c|c|c|c|c|c|}
\hline 1 & 2 & 3 & 4 & 5 & 6 & 7 & 8 \\
\hline $\begin{array}{l}\text { Wave- } \\
\text { length }\end{array}$ & $\begin{array}{l}\text { Tung- } \\
\text { sten } \\
\text { lamp } \\
\text { radiant } \\
\text { energy } \\
\text { per } \\
5 \mathrm{~m} \mu \text { at } \\
17.1 \mathrm{~cm}\end{array}$ & $\begin{array}{l}\text { Hg line } \\
\text { wave- } \\
\text { lengths }\end{array}$ & $\begin{array}{l}\text { Tung- } \\
\text { sten } \\
\text { lamp } \\
\text { energy } \\
\text { at Hg } \\
\text { line } \\
\text { positions }\end{array}$ & $\begin{array}{l}\text { Spectrom- } \\
\text { eter } \\
\text { recorder } \\
\text { integrated } \\
\text { response } \\
\text { for } 5 \text {-m } \mu \\
\text { band }\end{array}$ & $\begin{array}{c}\mathrm{Hg} \text { arc } \\
\text { lamp a } \\
\text { inten- } \\
\text { sities } \\
\text { at } 72.6 \\
\mathrm{~cm}\end{array}$ & $\begin{array}{l}\text { Spectrom- } \\
\text { eter } \\
\text { recorder } \\
\text { integrated } \\
\text { response } \\
\text { for } \\
0.25 \text {-mm } \\
\text { slits }\end{array}$ & $\begin{array}{l}\text { Ratio, } \\
\text { line to } \\
\text { continu- } \\
\text { ous } \\
\text { spectrum } \\
\text { response } \\
\text { columns } \\
\frac{4 \times 7}{5 \times 6}\end{array}$ \\
\hline $\begin{array}{c}m_{\mu} \\
300 \\
305\end{array}$ & $\begin{array}{c}\mu w / c m^{2} \\
0.94 \\
1.12\end{array}$ & $\begin{array}{c}m_{\mu} \\
302.4\end{array}$ & $\begin{array}{c}\mu w / c m^{2} \\
\text { per } 5 \\
-\cdots\end{array}$ & - & $\begin{array}{c}\mu w / \mathrm{cm}^{2} \\
\cdots\end{array}$ & -n... & ;..... \\
\hline $\begin{array}{l}310 \\
315\end{array}$ & $\begin{array}{l}\text { 1. } 23 \\
1.57\end{array}$ & 313.2 & 1. 48 & - & - & - & … \\
\hline $\begin{array}{l}360 \\
365 \\
370\end{array}$ & $\begin{array}{l}\text { 5. } 83 \\
\text { 6. } 57 \\
\text { 7. } 37\end{array}$ & 365.5 & 6.65 & (n) & 79. 63 & - & (n.... \\
\hline $\begin{array}{l}400 \\
405 \\
410\end{array}$ & $\begin{array}{l}\text { 13. } 48 \\
14.77 \\
16.06\end{array}$ & 405 & 14.77 & 0.207 & 31.75 & 0.421 & 0.946 \\
\hline $\begin{array}{l}430 \\
435 \\
440\end{array}$ & $\begin{array}{l}21.95 \\
23.59 \\
25.24\end{array}$ & 435.8 & 23.85 & .56 & 51. 43 & 1.05 & .870 \\
\hline $\begin{array}{l}540 \\
545 \\
550\end{array}$ & $\begin{array}{l}\text { 69. } 21 \\
71.74 \\
74.28\end{array}$ & 546.1 & 72.30 & 3. 27 & 57.30 & 2.27 & .876 \\
\hline $\begin{array}{l}570 \\
575 \\
580\end{array}$ & $\begin{array}{l}84.63 \\
87.19 \\
89.75\end{array}$ & 578 & 88.73 & 3.48 & 65.84 & 2.30 & .891 \\
\hline \multicolumn{7}{|c|}{$\begin{array}{l}\text { Mean } \\
\text { Multiplying factor- }\end{array}$} & $\begin{array}{l}0.896 \\
1.12\end{array}$ \\
\hline
\end{tabular}

a Not the identical lamp used for data of tables 1 and 2.

of the instrument aperture. The respective responses were obtained as area integrations of the plotted (or recorded) data for $5-\mathrm{m} \mu$ bands for the tungsten lamp and for the complete triangle in the case of each of the spectral lines for the mercury arc lamp. The values thus obtained for the four intense mercury emission lines (for 0.25 -mm slits) within the visible spectrum are evaluated in table 4. From this it appears that (for the spectrometer slit widths employed in most of the this work; namely $0.25 \mathrm{~mm}$ ) the spectral lines give responses on the average about 0.896 times that for an equal amount of continuous spectral radiant energy when integrated in this manner and based on a $5-\mathrm{m} \mu$ spectral interval. For wider spectrometer slits this factor is slightly larger, and for narrower slits slightly smaller. ${ }^{3}$ In the evaluation of spectral lines relative to continuous spectra the integrated values for the lines are therefore divided by 0.896 (or multiplied by 1.12) in the present investigation when $0.25-\mathrm{mm}$ slits are employed.

\section{Method Employed in Determining Spectroradi- ometer Response Factors}

The practical use of a spectrometer for the determination of the relative spectral energy distri-

\footnotetext{
3 Within the slit width range of 0.15 to $0.50 \mathrm{~mm}$ a change of 100 percent in the mechanical slit widths resulted in a change of about 10 percent in the intensity ratios between the line and continuous spectra.
}

bution of sources of radiant energy is dependent upon an accurate evaluation of all factors that affect the instrument output in relationship to the energy incident upon the entrance slit. Since in the apparatus herein described no condensing lens or mirror is employed between the lamp and the spectrometer slit, the radiant energy from the entire lamp, or from a representative portion of it in the case of a long fluorescent tube, enters the spectrometer without having undergone spectral distortion. However, within the spectrometer the lenses and prisms, and even the surface reflections, produce selective wavelength attenuation of the light beam. Furthermore, selective attenuation results from uncorrected errors in prism angles in their relationship to unavoidable mechanical defects in prism rotation and to slit alinement (especially in a three-slit instrument). The refractive characteristics of the prism material itself introduces a variable slit width factor. Differential loss of light at the margins of the optical apertures of the instrument as it is driven through the spectrum produces a selective spectral response effect. Hence, it is important that the light beams of the standard and unknown sources not only have closely the same geometrical characteristics, but that at all times the illuminated area remain well within the optical limits of the instrumental apertures. The detector, especially when it is a conventional phototube, has a response characteristic that is selective with wavelength.

The various factors that determine the response characteristic of a spectroradiometer may be determined by approaches from a number of directions and combined in the reduction of the data. Sometimes, however, it is difficult to obtain the required data for individual factor determinations. Partly because of this difficulty, but mainly because it was considered a more accurate method, all factors having to do with the spectral output response of the instrument were combined and determined experimentally by means of the standard tungsten-filament-inquartz lamp (supplemented by a color temperature standard [27 to 31$]$ ) and designated as the spectral response factor of the spectroradiometer. The spectral response factor is of course different for different

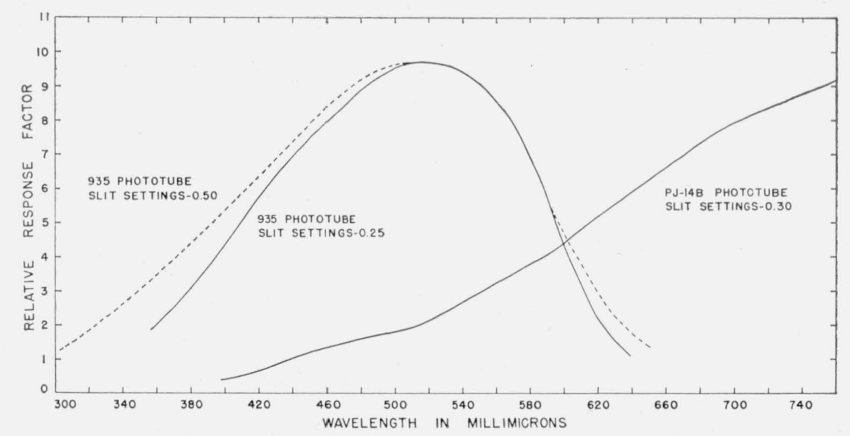

Figure 4. Relative spectral response factors for complete photoelectric spectroradiometer for selected phototubes and mechanical slit widths. 
mechanical slit widths or for different phototubes (see fig. 4). A slightly different curve is obtained if a color temperature standard is employed since the approximate spectral energy distribution associated with a standard of color temperature is somewhat high in both red and blue relative to the green [8]. In the present work the temperature standard (tungstenfilament-in-quartz lamp) is employed for all wavelengths shorter than about $510 \mathrm{~m} \mu$. Above this wavelength a mean between the temperature and color temperature standard is employed since much of the interest in the present work is in the field of color.

\section{Method Employed in Evaluating the Spectral Data}

The chart of the emission spectrum of a fluorescent lamp as observed represents not only the characteristics of the lamp emission but also such modifications as result because of the mechanical slit width and the relative spectral response factors for the instrument and phototube. (See fig. 4.)

The mechanical slit width affects not only the relative spectral response factors, but also the ratio of the integrated areas for the bright lines relative to the continuous spectra. Furthermore, the wider the slits the wider the triangle bases associated with the mercury emission lines and the less pure the continuous spectrum becomes. In the present work the mechanical slit widths were set at values such that there was a distinct separation between the 546 and $578-\mathrm{m} \mu$ lines. If the slits are set too narrow the transmitted energy reaches a level so low that signalto-noise ratio suffers. In the present work the mechanical slit widths chosen gave spectral-slit widths of about 5 to $10 \mathrm{~m} \mu$ within the visible spectrum.

The first step in the evaluation of the observed spectral data is to plot the smooth curve representing the continuous spectrum. (See fig. 5.) In this illustration the observed data in volts as read on the vacuum tube voltmeter are plotted (circles) as a function of wavelength. The solid curves represent the envelope of the energy distribution as drawn

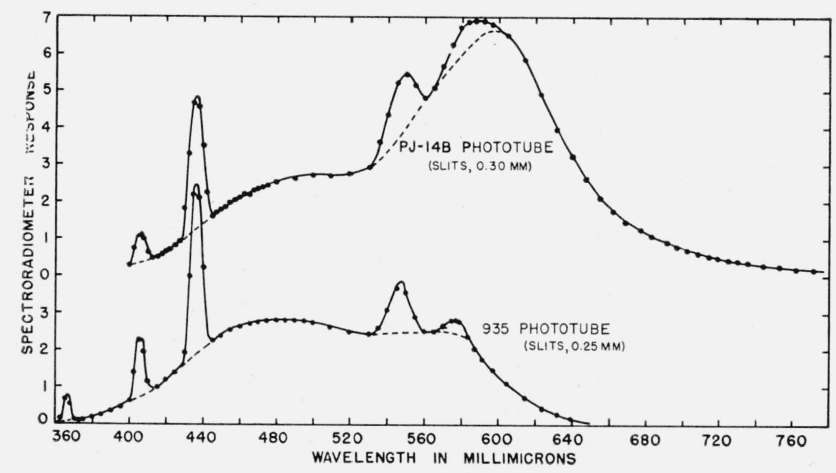

FiguRE 5. Spectroradiometer spectral response for a "daylight" fluorescent lamp.

Circles show voltage readings on VTVM for the indicated wavelengths for each phototube. See next figure for reducted spectral radiant energy distribution data for this lamp. by the recorder or as would be obtained by taking a very large number of voltage readings. Next the integrated areas of the triangles representing the mercury emission lines are determined and evaluated in terms of continuous spectrum areas per $5 \mathrm{~m} \mu$, centered at the wavelength of the mercury emission. The continuous spectrum curve is next reduced to relative spectral energy through the use of the spectrometer response factors (see fig. 4) and the data plotted (see figs. 6 to 9). Finally, energy values corresponding to the mercury emission lines as determined from the relative integrated areas after correction by the bright line to continuous spectrum ratio are plotted on the curves. They are shown as triangles whose bases are $10 \mathrm{~m} \mu$, as would be the case with fixed wavelength slits of $5-\mathrm{m} \mu$ spectral width.

The use of two phototubes, the one more sensitive to the snorter wavelengths and the other more sensitive to the longer wavelengths, has advantages comparable to that of a similar usage in the Beckman spectrophotometer $[35,36]$. The apparent shift in wavelength (see fig. 5) resulting in spectral regions wherein the photocell has an increasing (or decreasing) spectral response may cause difficulties if the shape of the energy distribution curve of the lamp under investigation differs too greatly from that of the standard. The mean between measurements with cells of the two types of spectral responses should give better data than obtainable with a single-cell type. In the present work (see fig. 5) the shapes of the curves in the spectral region between about 520 and $640 \mathrm{~m} \mu$ is a good example of what may be expected when the two types of photocells are used.

If it is desired to obtain an absolute evaluation of the total spectral radiant energy from the lamp at a specified distance and direction from the lamp it may be accomplished through the use of a filter (or combination) having a transmission band within the range of principal spectral emission of the lamp

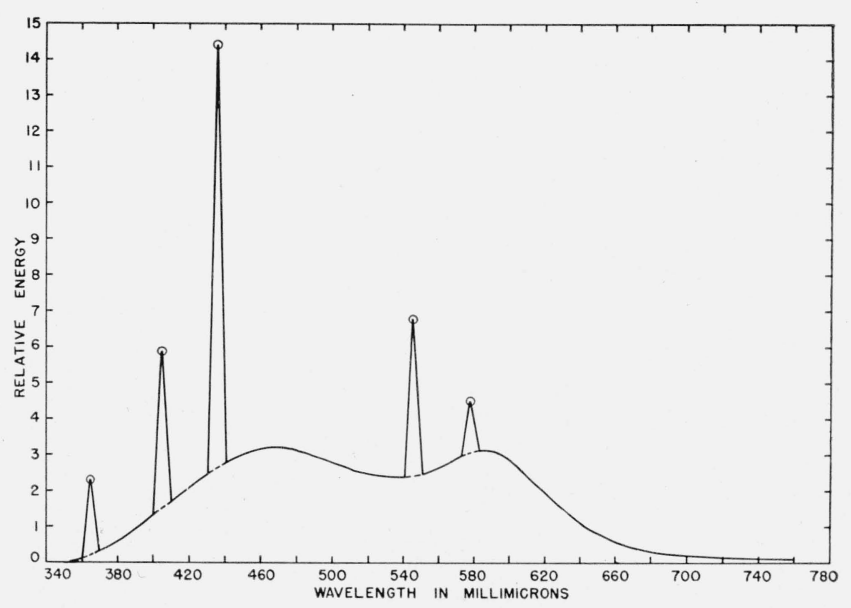

FiguRe 6. Relative spectral energy distribution of a "daylight" fluorescent lamp.

Lamp current $0.42 \mathrm{amp}$; room temperature $78^{\circ} \mathrm{F}$. 


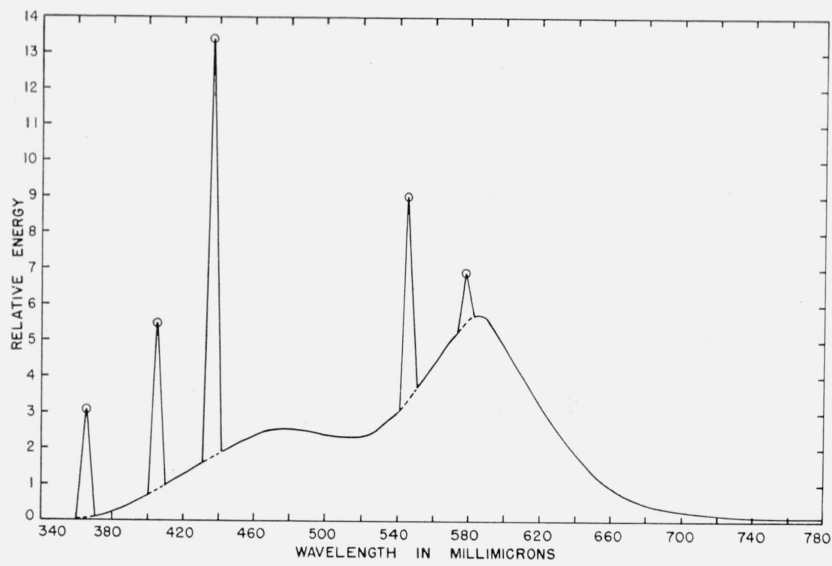

Figure 7. Relative spectral energy distribution of a "cool white" fluorescent lamp.

Lamp current $0.42 \mathrm{amp}$; room temperature $78^{\circ} \mathrm{F}$.

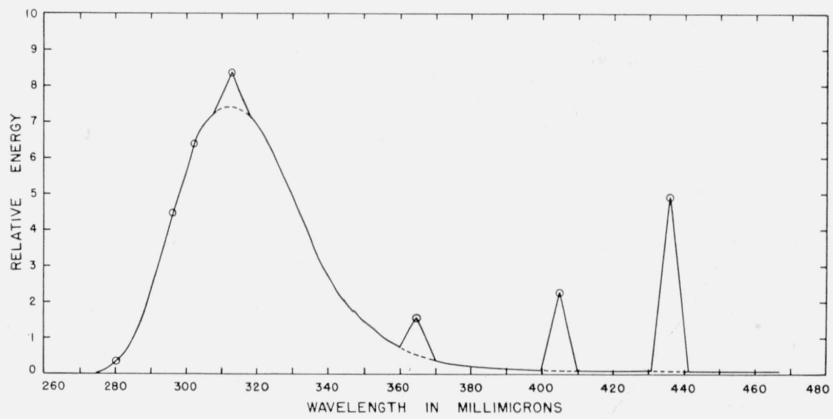

Figure 8. Relative spectral energy distribution of a fluorescent sun lamp.

Lamp current $0.37 \mathrm{amp}$; room temperature $78^{\circ} \mathrm{F}$.

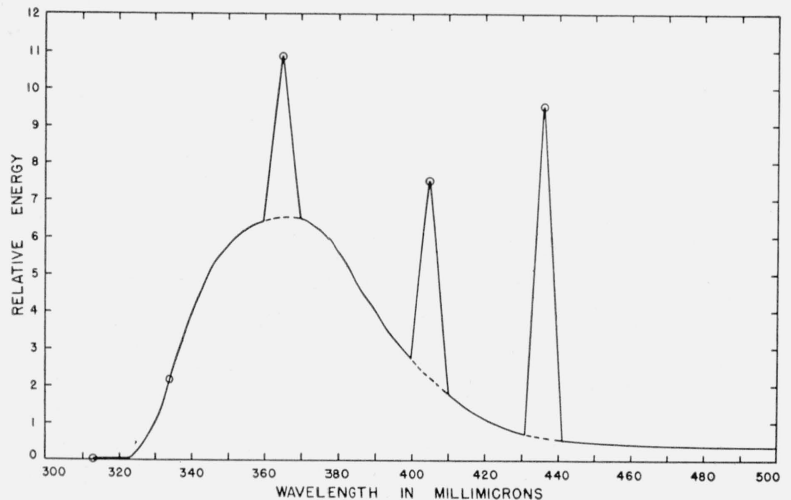

FiguRE 9. Relative spectral energy distribution of a fluorescent Black Light lamp. and the application of the method illustrated in table 3 for the tungsten-in-quartz lamp. The mercury emission lines are placed within the proper wavelength intervals or prorated between intervals in those cases where the wavelength of mercury emission is not closely coincident with the center of the wavelength interval chosen.

\section{Fluorescent Lamp Emission Spectra}

Fluorescent lamps employed for illuminating purposes appear to be made of varying quantities of two phosphors, one having a peak near $480 \mathrm{~m} \mu$ and the other near $590 \mathrm{~m} \mu$. Changes in composition or treatment of the phosphors result in varying emittance in the blue relative to that in the yellow-orange spectral region [16 to 20]. Hence, the lamps are thus made "white", "cool white", or "daylight", etc., in general color character. Special colors may be made by further control of the manufacturing process or through the use of dyes or colored tubing in the lamp manufacture.

As previously mentioned and illustrated in figures 5 to 9 , fluorescent lamps have an appreciable amount of radiant energy within the four visible mercury emission lines, 405, 435.8, 546.1, and $578 \mathrm{~m} \mu$. Hence their color is a combination of the two spectra. The phosphors employed control the continuous spectrum but have little effect upon the output of the mercury emission lines. In the illuminating lamps examined an appreciable amount of energy was present at $365.5 \mathrm{~m} \mu$. A small amount of radiant energy, often approximating 10 percent of the value at 365.5 was also observable at $313.2 \mathrm{~m} \mu$. The spectral energy distribution curves displayed were obtained on individual lamps available to the author and are reproduced primarily to illustrate the use of the methods and equipment employed.

As previously noted, a knowledge of the precise spectral energy distribution of a fluorescent lamp is important for use in the evaluation of its color characteristics. Using presently published data on the standard observer and evaluating the spectral data according to the $x, y, z$ coordinate system for colorimetry [31] a preliminary calculation on one "cool white" fluorescent lamp gave values of $x$ and $y$ of 0.372 and 0.357 as compared to 0.376 and 0.368 visually observed by members of the Colorimetry Laboratory of this Bureau. While the agreement is not exact, it should be considered good in view of the difficulties involved in the precise measurement of spectral energy distributions of this type and their proper color evaluation.

The fluorescent sun lamp is different from the ordinary illuminating fluorescent lamps only in the facts that its envelope is of a special ultraviolet transmitting glass (having a short-wave cut-off near $280 \mathrm{~m} \mu$ ) and that the phosphor employed is one having a fluorescence within the erythemal region (between about 300 and $360 \mathrm{~m} \mu$ ) of the spectrum [21 to 23]. In both cases the fluorescence is excited primarily by the energy emitted at the $2537-\mathrm{A}$ mercury line. Furthermore, in both cases any $2537-\mathrm{A}$ radiant 
energy not transformed by the phosphor is absorbed by the glass envelope.

In addition to the ultraviolet radiant energy emitted by sun lamps, the visible mercury emission lines are present in approximately the same relative intensities as found in the case of the illuminating lamps.

Fluorescent lamps may be constructed for any special use wherein radiant energy from any limited spectral region from about 290 to $800 \mathrm{~m} \mu$ may be useful. Such a lamp (BL-360) [21] having an application in black light experiments is illustrated in figure 8 .

\section{Discussion and Conclusions}

The method for evaluation of the relationship between the spectroradiometer response for line relative to continuous spectra is based entirely upon experimental data and permits a precise representation of the relative magnitudes of the two components in a mixed spectrum as found in a mercury type fluorescent lamp. Any peculiar mechanical or optical characteristics of a particular double instrument are thus taken into account by this method of calibration.

The high sensitivity of the amplifying and recording system employed in this instrument, together with its high signal-to-noise-ratio characteristics, is made possible through the use of a tuned modulation and amplifying arrangement. The choice of a frequency containing no harmonics of 60 or 120 cycles allows its use in the measurement of the radiant energy from a fluorescent lamp having almost 100-percent light modulation at 120 cycles.

The employment of alternating-current amplification permits a stable zero on the output meter or recorder, which allows continuous operation through the spectrum with no necessity for checking or for "guessing" where the "zero" was during the course of the measurements.

In the work herein displayed the accuracy of the data, especially for wavelengths shorter than about $400 \mathrm{~m} \mu$, depends upon the accepted value for the emissivity of tungsten. Above $510 \mathrm{~m} \mu$ the mean between a color temperature and a true temperature standard wherein published emissivity data were employed results in fluorescent-lamp spectra that are slightly higher (about 1 to $5 \%$ ) in the green and extreme red relative to the blue than if use had been made only of a color temperature standard. This difference is not great but indicates an urgent need for an accurate determination of the emissivity of tungsten. The high sensitivity and stability of the instrument herein described suggest its promising usefulness in this field.

Other investigations wherein this instrument is adaptable are those requiring precise measurements of low reflectivity or of high optical densities, for example the spectral transmittance of dark shade welding glass. Tests indicate full scale recorder traces for radiant energy through shade 12 glass having as a light source a 500-w incandescent lamp about 12 in. from the spectrometer entrance slit. Through the use of a condensing lens it should be possible to easily determine the spectral transmittance of a shade 14 welding glass. A preliminary study of the ultraviolet spectral distribution of radiant energy from the sun [32] indicates useful applications of this instrument for investigations of total atmospheric ozone.

\section{References}

[1] G. B. Buck II, Color preference studies with fluorescent lamps, Illum. Eng. 45, 165 (March 1950).

[2] R. L. Oetting and C. L. Amick, Interpretation of spectral distribution data in practical color applications, Trans. Illum. Eng. Soc. 36, 1369 (1941).

[3] Ralph Stair, A photoelectric meter for shade number classification of industrial eye-protective glasses, The Glass Ind. 30, 441 (1949).

[4] Ralph Stair, A precision radio instrument for transmitting measurements of ultraviolet intensities from unmanned balloons to a ground station, J. Research NBS 22, 295 (1939) RP1181.

[5] W. W. Coblentz and R. Stair, The present status of the standards of thermal radiation maintained by the Bureau of Standards, BS J. Research 11, 79 (1933) RP578.

[6] R. Stair and W. O. Smith, A tungsten-in-quartz lamp and its applications in photoelectric radiometry, J. Research NBS 30, 449 (1943) RP1543.

[7] W. W. Coblentz and R. Stair, A standard source of ultraviolet radiation for calibrating photoelectric dosage intensity meters, J. Research NBS 16, 83 (1936) RP858.

[8] W. E. Forsythe and A. G. Worthing, The properties of tungsten and the characteristies of tungsten lamps, Astrophys. J. 61, 146 (1925).

[9] H. C. Hamaker, Reflectivity and emissivity of tungsten Inaug. Diss. (Utrecht, Holland, 1934).

[10] F. Hoffman and H. Willenberg, Das Emissionsvermögen des wolframs im ultraviolett bei hohen temperaturen, Physik. Z. 35, 1, 711 (1934).

[11] L. S. Ornstein, Tables of the emissivity of tungsten as a function of wavelength from $0.23-2.0 \mu$ in the region of temperature $1600^{\circ}-3000^{\circ} \mathrm{K}$, Physica 3, 561 (1936).

[12] Mary P. Lord, Note on the measurement of spectral distribution when lines and continua are present together, Proc. Phys. Soc. 58, 477 (1946).

[13] Charles W. Jerome, The determination of color parameters of fluorescent lamps, Illum. Eng. 45, 225 (1950).

[14] S. L. Parsons, Alfred E. Martin, and S. N. Roberto, Recording spectroradiometers for luminescent materials, J. Electrochem. Soc. 97, 41 (1950).

[15] W. E. Forsythe and B. T. Barnes, A large crystalline quartz double monochromator, Rev. Sci. Instr. 4, 289 (1933).

[16] K. H. Butler, Emission spectra of silicate phosphors with manganese activation, J. Electrochem. Soc. 93, 143 (1948).

[17] Keith H. Butler, Barium silicate phosphors, Trans. Electrochem. Soc. 91, 265 (1947)

[18] Keith H. Butler and James G. Cassanos, Bariummagnesium silicate phosphors, J. Electrochem. Soc. 97, 83 (1950).

[19] Herman C. Froelich, Manganese activated calcium silicate phosphors, Trans. Electrochem. Soc. 93, 101 (1948).

[20] Gorton R. Fonda and Herman C. Froelich, The structure of silicate phosphors, Trans. Electrochem. Soc. 93, 114 (1948).

[21] H. C. Froelich, New ultraviolet phosphors, Trans. Electrochem. Soc. 91, 241 (1947).

[22] R. H. Clapp and R. J. Ginther, Ultraviolet phosphors and fluorescent sun tan lamps, J. Opt. Soc. Am. 3\%, 355 (1947). 
[23] Rudolph Nagy, R. W. Wollentin, and C. K. Lui, Ultraviolet-Emitting phosphor, J. Electrochem. Soc. 97, $29(1950)$.

[24] J. F. Skogland, Tables of spectral energy distribution and luminosity for use in computing light transmission and relative brightnesses from spectrophotometric data, NBS Misc. Pub. M86 (1929).

[25] Parry Moon, Table of Planck's function from $3500^{\circ}$ to $8000^{\circ} \mathrm{K}$ (Mass. Inst. of Tech., Cambridge, Mass.)

[26] M. Katherine Frehafer and Chester L. Snow, Tables and graphs for facilitating the computation of spectral energy distributions by Planck's formula, NBS Misc. Pub. M56 (1925).

[27] H. T. Wensel, D. B. Judd, and W. F. Roeser, Establishment of a scale of color temperature, BS J. Research 12, 527 (1934) RP677.

[28] H. F. Stimson, The international temperature scale of 1948, J. Research NBS 42, 209 (1949) RP1962.

[29] Robert J. Corruccini, Differences between the international temperature scale of 1948 and 1927, J. Research NBS 43, 133 (1949) RP2014.
[30] Deane B. Judd, The 1949 scale of color temperature, J. Research NBS 44, 1 (1950) RP2053.

[31] Deane B. Judd, The 1931 I. C. I. standard observer and coordinate system for colorimetry, J. Opt. Soc. Am. 23, 359 (1933).

[32] Ralph Stair, The Ultraviolet spectral distribution of the radiant energy from the sun, J. Research NBS 46, 353 (1951) RP2206.

[33] W. R. Plant, A new recording spectroradiometer, J. Opt. Soc. Am. 40, 805 (1950).

[34] F. J. Studer and W. R. Jacobson, Spectroradiometry, Gen. Elec. Rev. 52, (Oct. 1949).

[35] H. H. Cary and Arnold O. Beckman, A quartz photoelectric spectrophotometer, J. Opt. Soc. Am. 31, 682 (1941).

[36] Kasson S. Gibson and Margaret M. Balcom, Transmission measurements with the Beckman quartz spectrophotometer, J. Research NBS 38, 601 (1947) RP1798.

Washington, September 25, 1950. 